\title{
REVIEW OF CONSTRUCTION SUPPLY CHAIN OPTIMIZATION PAPERS FOR PERFORMANCE IMPROVEMENT
}

\author{
Muhamamd Atiq Ur Rehman', Amin Chaabane², and Sharfuddin Ahmed Khan ${ }^{3}$
}

\begin{abstract}
For many countries, improving the construction sector's productivity is becoming more critical for achieving a sustainable long-term competitive advantage. Moreover, the construction industry is increasingly considering digitization, automation, and Information and Communications Technology (ICT) to achieve this objective. Advanced analytics application in supply chain optimization plays a critical role in supporting enterprise performance optimization in many sectors.

Therefore, this research aims to provide researchers with an overview of the recent developments of optimization techniques on the construction supply chain (CSC) for maximizing performance or minimizing cost and highlight the current research gaps in the field. The systematic desk methodology has been used in this research.

The findings of this study shows that there is need of a framework that integrate all CSC processes for its overall optimization as very few studies incorporated design phase processes with procurement and execution phase processes in their optimization model.
\end{abstract}

\section{KEYWORDS}

Off-site construction, supply chain management, modular construction, optimization, Integration.

\section{INTRODUCTION}

Construction supply chain management (CSCM) comes with challenges such as lack of collaboration among construction project stakeholders, lack of knowledge transferring and sharing capabilities, lack of standardization and lack of process integration(Saini, Arif, \& Kulonda, 2019) and its optimization for maximizing productivity and minimizing project cost is even greater complex and challenging because CSC involves multiple players and such as owner, designer, contractor, sub-contractor, and outsources labor and processes such as manufacturing, warehousing, inventory, transporation and execution at construction site.These stakeholders and processes are interdependent to each other at different levels of a project.

$1 \quad$ PhD Student, Department of Systems Engineering,École de technologie supérieure ÉTS, 1100 Notre-Dame St W, Montreal, Quebec H3C 1K3, Canada, muhammad.atiq-ur-rehman.1 @ens.etsmtl.ca, orcid.org/0000-0001-9659-9510

2 Associate Professor, Department of Systems Engineering, École de technologie supérieure ÉTS, 1100 Notre-Dame St W, Montreal, Quebec H3C 1K3, Canada, amin.chaabane@ etsmtl.ca, orcid.org/00000002-1113-7630

3 Assistant Professor, Department of Industrial Engineering,University of Sharjah, University City Rd, University City ,Sharjah ,UAE, skhan@sharjah.ac.ae, orcid.org/0000-0002-5822-0933 
In addition to this, the stakeholders' benefits and requirements are conflicting as well so it is intricate to achieve a win-win situation for every stakeholder in a construction project. Also, lack of engagement during project lifecycle results in over budget and longer duration for a construction project completion and due to these reasons small and medium-sized companies are way behind reaping optimized integration benefits involved in a construction project. (Bahadorestani, Naderpajouh, \& Sadiq, 2020). Consequently, in order to optimize overall CSC of a project and avoiding any conflict, all the processes and their effects must be incorporated in a model developed for maximizing performance of a project.So there is need of a research that provide comprehensive overview of existing papers focused on application of optimization on CSC processes.

Therefore, in this study, an attempt has been made to review the CSCM optimization papers that incorporated major CSC processes in their model and identify research gaps for further improvement in this area.

\section{LITERATURE REVIEW}

There are few studies that reviewed CSCM papers but they were not related with optimization application. One review study was related to enablers in CSC (Q. Chen, Hall, Adey, \& Haas, 2020), one was related with decision making in CSC (Phuoc Luong Le, Elmughrabi, Dao, \& Chaabane, 2020) and the other was done on the development of framework for SC planning consist of construction process critera(Thunberg, 2016).Furthermore, one paper reviewed CSC papers in the context of industry 4.O (Dallasega, Rauch, \& Linder, 2018) and one paper review is related with internet of things(Kumar \& Shoghli, 2018) .Thus this study is going to be first of its kind that reviewed CSC optimization papers against SC processes.

To review the CSC optimization papers, a benchmark or refrence list of exhastuive $\mathrm{SC}$ processes was required to evaluate review papers against those processes.(Y. Liu, Dong, \& Shen, 2020) and (Phuoc Luong Le et al., 2020) identified the CSC levels, phases and processes in a very comprehensive manner is presented in table 1 . These processes is taken as benchmark and review of CSC optimization papers is carried out based on these processes in this study.

Table 1: Phases and Processes in Construction Supply Chain Management

\begin{tabular}{|c|c|c|c|c|c|c|c|c|c|c|c|}
\hline \multicolumn{8}{|c|}{ Collaboration Level } & \multicolumn{4}{|c|}{ Execution level } \\
\hline \multicolumn{3}{|c|}{ Design Phase } & \multicolumn{5}{|c|}{ Procurement Phase } & & Constru & on Phase & \\
\hline 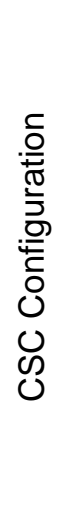 & 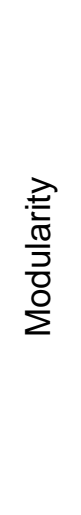 & 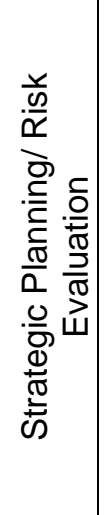 & 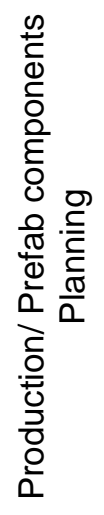 & 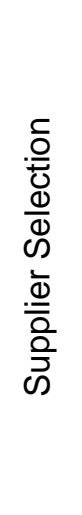 & 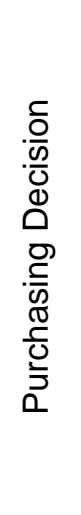 & $\begin{array}{l}0 \\
\Phi \\
\bar{\varpi} \\
\stackrel{0}{\omega}\end{array}$ & 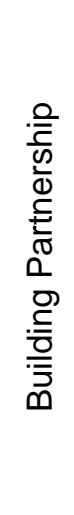 & 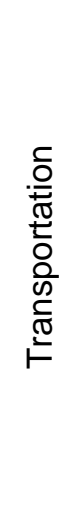 & 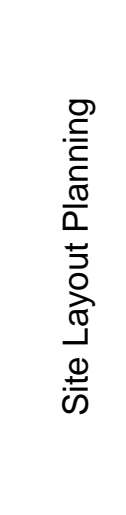 & 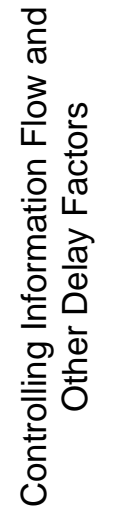 & 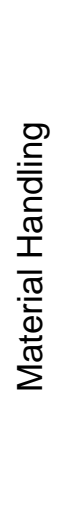 \\
\hline
\end{tabular}


- CSC Configuration (CC): To configure and allocate CSC factors, SC participants, material and information flows, strategies, and resources of the SC network.

- Modularity (M): To determine the modularity of a building under controlled conditions.

- Strategic Planning/ Risk Evaluation (SR): To identify, assess risks, raise mitigation and contingency strategies, and respond efficiently to recognized threats as they arise. Production/Prefab Components Planning (PP): To make and control the construction project's production plan and manufacturing processes.

- Supplier Selection (SS): To apply efficient methods for supplier evaluation \& selection.

- Purchasing Decision (PD): To employ the efficient methods for material procurement.

- Storage(S): To figure out the most cost-effective warehousing of prefab components.

- Building Partnership (BP): To apply SCM in construction to achieve long-term and supportive partnerships among stakeholders to ensure project cost optimization

- Transportation (T): To establish and control the transportation system (Off \& OnSite).

- Site Layout Planning (SLP): To improve the on-site construction performance by optimizing the arrangement of facilities.

- Controlling Information Flow and Other Delay Factors (CD): To control information and physical flows to avoid instability in construction execution.

- Material Handling (MH): To convey, elevate, position, transport, package, and store materials and facilities management.

\section{RESEARCH METHOD}

A systematic literature review has been carried out in this research. This approach is adopted from the papers (Seuring \& Gold, 2012) and (Khan, Chaabane, \& Dweiri, 2018), and it of papers (Mettler, Eurich, \& Winter, 2014).

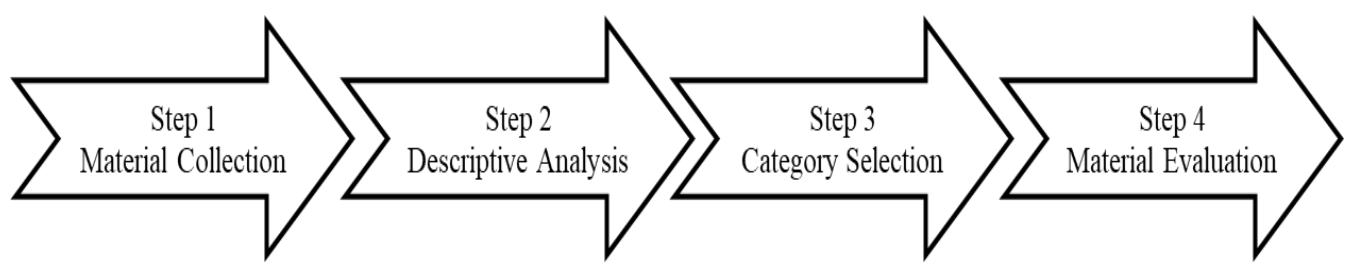

Figure1: Literature Review Method

- Step1: The Scopus database has been used in this research because it covers a superior number of journals and articles (Aghaei Chadegani et al., 2013). Unpublished work, non-reviewed papers, working papers, and book chapters are not considered in this study. The keyword search approach is used because it is the most common way of literature review in databases and library services (Seuring \& Gold 2012). The different keywords and their combination results are shown in Table 2. 
Table 2: Selected Keywords Combination Search Results

\begin{tabular}{cc}
\hline Keywords Combination & Search Results \\
\hline Construction Supply Chain AND Optimization AND Logistics & 99 \\
Construction Supply Chain AND Optimization AND Material Planning & 31 \\
Construction Industry AND Optimization AND Supply Chain & 146 \\
Construction Industry OR Building AND Supply Chain & 471 \\
Building AND Optimization AND Supply Chain & 536 \\
Construction Supply Chain AND Modular AND Optimization & 17 \\
Building AND Optimization AND Logistics & 291 \\
Construction AND Supply Chain AND Optimization & 516 \\
Construction AND Supply Chain AND Improvement & 522 \\
Construction AND Logistics AND Optimization & 726 \\
Construction AND Logistics AND Improvement & 506 \\
Construction AND Material Planning AND Optimization & 647 \\
Construction AND Material Planning AND Improvement & 591 \\
Building AND Supply Chain AND Improvement & 431 \\
\hline
\end{tabular}

- Step2: After searching papers using different keywords combination, filtration of those papers was done through the criteria: If a paper studied or implement the application of optimization tools on construction supply chain processes as identified in this paper, that paper was selected. 41 papers were finalized after step 2 , as shown in below graph 1 .

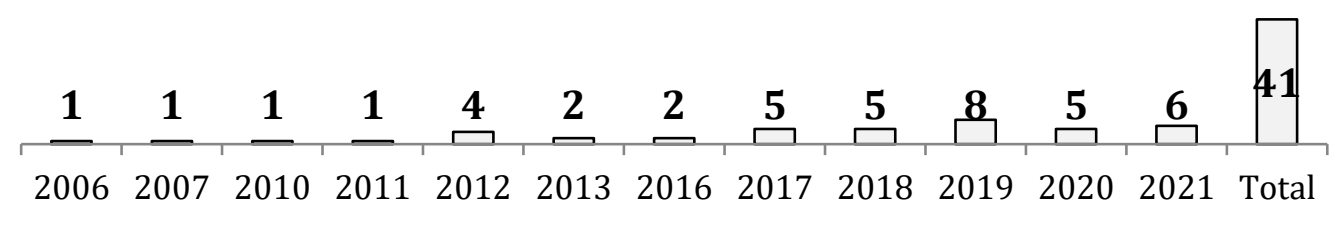

Graph 1: Year Wise break up of Selected Papers

- Step3: Categorized them on the basis of optimization tools and CSC processes.

- Step4: Evaluation of selected papers was done by reading the article's abstract, methodology, and conclusion. Then, identify what and how many supply chain process factors are incorporated in a paper's mathematical model. This material evaluation process was based on all authors' academic judgment, and crossreading was performed to eliminate the discrepancy in understanding among authors for material evaluation.

- Step5: An additional step is also taken, which is not a part of this approach. The optimization tools identified in the papers mentioned in table 3 are verified with the literature definition of the tools to ensure correct understanding of the tools concept. 


\section{RESULTS}

In line with the first research objective of this study, analysis was done on the filtered papers against CSC processes and optimization tools as mentioned in table 3. As mentioned in Table 3, the MCDM tool is found to be the most used optimization technique. In CSC, out of 41 papers, 25 and 24 articles have focused on CSC's transportation and purchasing decision processes, followed by the storage process, which has been studied 21 times. At the same time, CSC configuration and strategic planning received the least attention from the authors as only six studies have focused on them. The process such as material handling, site layout planning, and supplier selection has been studied moderately.Following is the analysis of table 3 findings:

\section{Design Phase}

Collaboration level processes received the least attention relatively with the rest of the processes. Only 19 papers from 44 have focused at least on one of the management-level processes. Very limited numbers of papers were found that used mathematical tools to develop construction supply chain configuration and strategic management, so the application of mathematical tools is still not very mature or underexploited.

\section{Procurement Phase}

Most of the studies on CSC have focused on planning-level processes. Thirty-six papers from 44 have contributed to at least one of the CSC procurement phase processes as mentioned in Table3. Multi-criteria decision-making tools have been applied successfully in mostly supplier selection problems. Operation research modeling such as linear, integer, or even mixed-integer linear programming models along with stochastic models has been used to tackle manufacturing planning, material ordering, and storage issues of construction material and prefabricated components.

\section{Construction Phase}

32 papers have focused on at least any one of the processes of this phase. Hybrid models, simulation techniques, and multi-criteria decision-making have been applied to predict delays on construction sites and supply material transportation. Using mathematical models for optimizing transportation processes is very mature in other sectors and looks promising in other processes as well. 


\begin{tabular}{|c|c|c|c|c|c|c|c|c|c|c|c|c|c|}
\hline Authors & Optimization Tool & $\mathrm{CC}$ & ML & SR & PP & ss & PD & $\mathbf{s}$ & BP & $\mathrm{T}$ & $\overline{\text { SL }}$ & $\mathrm{CD}$ & $\mathrm{MH}$ \\
\hline (Elimam \& Dodin, 2013) & MILP & & & & $\sqrt{ }$ & $\sqrt{ }$ & $\sqrt{ }$ & $\sqrt{ }$ & & $\sqrt{ }$ & & & \\
\hline (Alayet, Lehoux, \& Lebel, 2018) & LP & & & & $\sqrt{ }$ & & & $\sqrt{ }$ & & $\sqrt{ }$ & & & \\
\hline (Cengiz, Aytekin, Ozdemir, Kusan, \& Cabuk, 2017) & MCDM & & & & & $\sqrt{ }$ & & & $\sqrt{ }$ & & & & \\
\hline (Q. Chen, García de Soto, \& Adey, 2021) & NLP & & & & & & $\sqrt{ }$ & $\sqrt{ }$ & $\sqrt{ }$ & $\sqrt{ }$ & & & \\
\hline (W. W. Chen, Lei, Wang, Teng, \& Liu, 2018) & MILP & & & & & $\sqrt{ }$ & $\sqrt{ }$ & $\sqrt{ }$ & & $\sqrt{ }$ & & & $\sqrt{ }$ \\
\hline (Costa, Granja, Fregola, Picchi, \& Staudacher, 2019) & MCDM & $\sqrt{ }$ & & $\sqrt{ }$ & & & & & $\sqrt{ }$ & & & $\sqrt{ }$ & \\
\hline (Deng, Gan, Das, Cheng, \& Anumba, 2019) & NLP & & & & & $\sqrt{ }$ & $\sqrt{ }$ & $\sqrt{ }$ & $\sqrt{ }$ & $\sqrt{ }$ & $\sqrt{ }$ & & $\sqrt{ }$ \\
\hline (Hemanth et al., 2017) & MCDM & & & $\sqrt{ }$ & & & & & $\sqrt{ }$ & & & $\sqrt{ }$ & \\
\hline (Hsieh, 2016) & Hybrid Methods & & & & & & & & & $\sqrt{ }$ & $\sqrt{ }$ & $\sqrt{ }$ & \\
\hline (P. Y. Hsu, Angeloudis, \& Aurisicchio, 2018) & $\begin{array}{l}\text { Two-stage Stochastic } \\
\end{array}$ & & $\sqrt{ }$ & & $\sqrt{ }$ & $\sqrt{ }$ & $\sqrt{ }$ & $\sqrt{ }$ & & $\sqrt{ }$ & & & \\
\hline (P. Y. Hsu, Aurisicchio, \& Angeloudis, 2017) & MILP & & $\sqrt{ }$ & & $\sqrt{ }$ & $\sqrt{ }$ & $\sqrt{ }$ & $\sqrt{ }$ & $\sqrt{ }$ & $\sqrt{ }$ & & & \\
\hline (P.-Y. Hsu, Aurisichhio, \& Angeloudis, 2019) & Hybrid Methods & & $\sqrt{ }$ & & & $\sqrt{ }$ & $\sqrt{ }$ & $\sqrt{ }$ & & $\sqrt{ }$ & $\sqrt{ }$ & $\sqrt{ }$ & \\
\hline (JaŚkowski, Sobotka, \& Czarnigowska, 2018) & MILP & & & & & $\sqrt{ }$ & $\sqrt{ }$ & $\sqrt{ }$ & & . & & & \\
\hline (Karabayir, Botsali, Kose, \& Cevikcan, 2020) & MCDM & & & & & $\sqrt{ }$ & 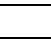 & & & & & & \\
\hline (Kayhan, Cebi, \& Kahraman, 2019) & MCDM & & & $\sqrt{ }$ & & $\sqrt{ }$ & $\sqrt{ }$ & & & 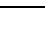 & & & \\
\hline (S. Kim, Chang, \& Castro-Lacouture, 2020) & Simulation methods & & & & & & & 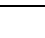 & & & & $\sqrt{ }$ & \\
\hline (T. Kim, Kim, \& Cho, 2020) & Simulation methods & & & $\sqrt{ }$ & $\sqrt{ }$ & & & 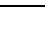 & & $\sqrt{ }$ & $\sqrt{ }$ & $\sqrt{ }$ & $\sqrt{ }$ \\
\hline (Y. W. Kim, Han, Yi, \& Chang, 2016) & Simulation methods & $\sqrt{ }$ & & & $\sqrt{ }$ & & $\sqrt{ }$ & $\sqrt{ }$ & & $\sqrt{ }$ & & & \\
\hline (Komsiyah, Wongso, \& Pratiwi, 2019) & MCDM & & & & & $\sqrt{ }$ & & & $\sqrt{ }$ & . & & & \\
\hline (Kristy \& Zagloel, 2020) & MCDM & & & & & $\sqrt{ }$ & & & $\sqrt{ }$ & & & & \\
\hline (Leontaris, Morales-Nápoles, Dewan, \& Wolfert, 2019) & $\begin{array}{l}\text { Simulation methods } \\
\end{array}$ & & & $\sqrt{ }$ & & & $\sqrt{ }$ & $x$ & & $\sqrt{ }$ & $\sqrt{ }$ & $\sqrt{ }$ & $\sqrt{ }$ \\
\hline (van der Beek, van Essen, Pruyn, Aardal, \& Hopman, 2019) & MILP & & $\sqrt{ }$ & & $\sqrt{ }$ & & $\sqrt{ }$ & $\sqrt{ }$ & & 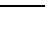 & & & \\
\hline (J. Liu \& Lu, 2017) & LP & & $\sqrt{ }$ & & & & $\sqrt{ }$ & & & $\sqrt{ }$ & & $\sqrt{ }$ & $\sqrt{ }$ \\
\hline (Yazdi, Fini, \& Forsythe, 2020) & LP & & $\sqrt{ }$ & & $\sqrt{ }$ & & & & & & $\sqrt{ }$ & & \\
\hline (Jing Liu \& Lu, 2018) & Hybrid Methods & & $\sqrt{ }$ & $\sqrt{ }$ & $\sqrt{ }$ & & $\sqrt{ }$ & & & $\sqrt{ }$ & & $\sqrt{ }$ & $\sqrt{ }$ \\
\hline (Tserng, Yin, \& Li, 2006) & Constraint Programming & & & & $\sqrt{ }$ & & $\sqrt{ }$ & $\sqrt{ }$ & $\sqrt{ }$ & $\sqrt{ }$ & & & \\
\hline (Castro-Lacouture, Medaglia, \& Skibniewski, 2007) & LP & & & & & & & $\sqrt{ }$ & & & & & \\
\hline (Taghaddos, Hermann, AbouRizk, \& Mohamed, 2010) & Simulation & & $\sqrt{ }$ & & $\sqrt{ }$ & & $\sqrt{ }$ & $\sqrt{ }$ & & $\sqrt{ }$ & $\sqrt{ }$ & $\sqrt{ }$ & $\sqrt{ }$ \\
\hline (Pan, Lee, \& Chen, 2011) & LP & $\sqrt{ }$ & & & & $\sqrt{ }$ & $\sqrt{ }$ & $\sqrt{ }$ & & $\sqrt{ }$ & & & \\
\hline (Cadena, Ramos, Gómez, \& Munoz, 2012) & MILP & & & & & & & & & & $\sqrt{ }$ & $\sqrt{ }$ & $\sqrt{ }$ \\
\hline (D. Liu, 2012) & Genetic Algorithm & $\sqrt{ }$ & & & & & & & & & & & \\
\hline (Said \& El-Rayes, 2012) & Genetic Algorithm & & & & & & $\sqrt{ }$ & $\sqrt{ }$ & & $\sqrt{ }$ & $\sqrt{ }$ & & $\sqrt{ }$ \\
\hline (Xanthopoulos, Aidonis, Vlachos, \& Iakovou, 2012) & LP & & & & & & & & & & $\sqrt{ }$ & $\sqrt{ }$ & $\sqrt{ }$ \\
\hline (Said \& El-Rayes, 2013) & Hybrid Methods & $\sqrt{ }$ & & & & & $\sqrt{ }$ & $\sqrt{ }$ & $\sqrt{ }$ & $\sqrt{ }$ & $\sqrt{ }$ & $\sqrt{ }$ & \\
\hline (J. H. Chen, Yan, Tai, \& Chang, 2017) & Linear Programming & & & & $\sqrt{ }$ & & & & & $\sqrt{ }$ & & & \\
\hline (Golkhoo \& Moselhi, 2019) & Hybrid Methods & & & & & & $\sqrt{ }$ & $\sqrt{ }$ & & $\sqrt{ }$ & & $\sqrt{ }$ & $\sqrt{ }$ \\
\hline (Jaafar, Elbarkouky, \& Kennedy, 2021) & MILP & & & & & & & & & & $\sqrt{ }$ & $\sqrt{ }$ & $\sqrt{ }$ \\
\hline (P. L. Le, Jarroudi, Dao, \& Chaabane, 2021) & LP & & & & & $\sqrt{ }$ & $\sqrt{ }$ & $\sqrt{ }$ & $\sqrt{ }$ & $\sqrt{ }$ & & & \\
\hline (Mirghaderi \& Modiri, 2021) & Hybrid Methods & $\sqrt{ }$ & & & $\sqrt{ }$ & & $\sqrt{ }$ & $\sqrt{ }$ & & $\sqrt{ }$ & & & $\sqrt{ }$ \\
\hline (Son, Duy, \& Dat, 2021) & Hybrid Methods & & & & $\sqrt{ }$ & & $\sqrt{ }$ & $\sqrt{ }$ & & $\sqrt{ }$ & & & \\
\hline (Zhu, Dai, Liu, Xu, \& Alwisy, 2021) & LP & & $\sqrt{ }$ & & $\sqrt{ }$ & & $\sqrt{ }$ & & & $\sqrt{ }$ & & $\sqrt{ }$ & $\sqrt{ }$ \\
\hline \multicolumn{2}{|l|}{ Total papers / CSC Proce } & 6 & 9 & 6 & 15 & 14 & 24 & 21 & 11 & 25 & 12 & 16 & 14 \\
\hline
\end{tabular}




\section{DISCUSSION}

\section{RESEARCH OPPORTUNITY (RO) 1}

\section{"Best Decision-Making Tool for Each Construction Supply Chain Process"}

There are papers where operations research is applied to the construction supply chain process, and some papers even try to cover the whole aspect of the construction supply chain. However, there is still a lack of research that identifies the best decision-making tool for each supply chain aspect. For example, Fuzzy AHP is most recommended for supplier selection as identified from the literature review (Su, 2020) but it is not adequate for other processes such as demand prediction where stochastic models may work well. Therefore, research is needed to find the best decision-making tool for each supply chain construction process that can incorporate uncertainties and scenarios of that process.

\section{RESEARCH OPPORTUNITY 2}

\section{"Framework for Optimizing Overall Construction Supply Chain"}

There is a need for a framework to identify the best practice to optimize the overall construction supply chain. That framework will include phases and processes like mentioned in this research and the best tools for each process mentioned in research gap that framework will also identify how to integrate each process's best results to optimize the overall construction supply chain to produce the most effective results.(S.-Y. Kim \& Nguyen, 2020) also identified factors that are barrier in effective CSC implementation, some barriers were lack of involvement in active participation from parties and lack of knowledge of applied SCM etc , so their study can be helpful for this research opportunity.

\section{RESEARCH OPPORTUNITY 3}

\section{"Standardizing Supply Chain processes through Lean Construction."}

Recent trend shows that researchers have recommended lean construction. The research can be done on standardizing construction supply chain processes. Lean management is about removing things that do not add value to the cause; that can be an operation or/an excess of anything such as cost, time utilized in executing any function. Therefore, standardization of construction supply chain processes through lean management tools such as Value Stream Mapping (VSM) can be a critical first step before optimizing or improving those processes.Similar opportunity was identified by (Dana Broft, 2020) where they proposed combine usage of SC and lean pricnicples for effective CSCM.

\section{CONCLUSION}

An attempt has been made in this research to identify and analyze the papers related to the application of optimization tools to maximize performance or minimize the cost of CSC. Forty-one papers were analyzed against 12 processes of CSC, and none of them were covering all the processes in their optimization model. Design-level processes are qualitative and not easy to incorporate them into the model. Still, their factors and effects can be incorporated in future optimization tools to comprehend all the processes and optimize CSC effectively. This is the major research opportunity identified in this research. However, to achieve this effectively, it is needed to identify the best decisionmaking tool for each process (RO 1) and then incorporate all the processes and their effects, especially design level qualitative processes, in a mathematical model (RO 2). 
This research has some limitations. Indeed, only the Scopus database has been used to explore papers, so a web of science database could be added for future research. Finally, this research focuses only on CSC optimization. Therefore, doing the same research from different methodology/technique perspective could also be done in the future.

\section{REFRENCES}

Aghaei Chadegani, A., Salehi, H., Yunus, M., Farhadi, H., Fooladi, M., Farhadi, M., \& Ale Ebrahim, N. (2013). A comparison between two main academic literature collections: Web of Science and Scopus databases. Asian social science, 9(5), 18-26.

Alayet, C., Lehoux, N., \& Lebel, L. (2018). Logistics approaches assessment to better coordinate a forest products supply chain. Journal of Forest Economics, 30, 13-24.

Bahadorestani, A., Naderpajouh, N., \& Sadiq, R. (2020). Planning for sustainable stakeholder engagement based on the assessment of conflicting interests in projects. Journal of Cleaner Production, 242, 118402.

Cadena, J. E., Ramos, M. A., Gómez, J. M., \& Munoz, F. (2012). Facility layout optimization detailed research through MILP and MINLP. Paper presented at the Global Congress on Process Safety 2012 - Topical Conference at the 2012 AIChE Spring Meeting and 8th Global Congress on Process Safety.

Castro-Lacouture, D., Medaglia, A. L., \& Skibniewski, M. (2007). Supply chain optimization tool for purchasing decisions in B2B construction marketplaces. Automation in Construction, 16(5), 569-575.

Cengiz, A. E., Aytekin, O., Ozdemir, I., Kusan, H., \& Cabuk, A. (2017). A Multi-criteria Decision Model for Construction Material Supplier Selection. Paper presented at the Procedia Engineering.

Chen, J. H., Yan, S., Tai, H. W., \& Chang, C. Y. (2017). Optimizing profit and logistics for precast concrete production. Canadian Journal of Civil Engineering, 44(6), 393406.

Chen, Q., García de Soto, B., \& Adey, B. T. (2021). Supplier-contractor coordination approach to managing demand fluctuations of ready-mix concrete. Automation in Construction, 121, 103423.

Chen, Q., Hall, D. M., Adey, B. T., \& Haas, C. T. (2020). Identifying enablers for coordination across construction supply chain processes: a systematic literature review. Engineering, Construction and Architectural Management.

Chen, W. W., Lei, L., Wang, Z. W., Teng, M. F., \& Liu, J. M. (2018). Coordinating supplier selection and project scheduling in resource-constrained construction supply chains. International Journal of Production Research, 56(19), 6512-6526.

Costa, F., Granja, A. D., Fregola, A., Picchi, F., \& Staudacher, A. P. (2019). Understanding Relative Importance of Barriers to Improving the Customer-Supplier Relationship within Construction Supply Chains Using DEMATEL Technique. Journal of Management in Engineering, 35(3).

Dallasega, P., Rauch, E., \& Linder, C. (2018). Industry 4.0 as an enabler of proximity for construction supply chains: A systematic literature review. Computers in Industry, 99, 205-225.

Dana Broft, R. (2020). Lean Supply Chain Management in Construction: Implementation at the 'Lower Tiers' of the Construction Supply Chain. Successful Construction Supply Chain Management: Concepts and Case Studies, 271-287. 
Deng, Y., Gan, V. J. L., Das, M., Cheng, J. C. P., \& Anumba, C. (2019). Integrating 4D BIM and GIS for Construction Supply Chain Management. Journal of Construction Engineering and Management, 145(4).

Elimam, A. A., \& Dodin, B. (2013). Project scheduling in optimizing integrated supply chain operations. European Journal of Operational Research, 224(3), 530-541.

Golkhoo, F., \& Moselhi, O. (2019). Optimized material management in construction using multi-layer perceptron. Canadian Journal of Civil Engineering, 46(10), 909923.

Hemanth, G., Sidhartha, C., Jain, S., Saihanish, P., Rohit, V., \& Ieee. (2017). AHP analysis for using Cloud Computing in Supply Chain Management in the Construction Industry.

Hsieh, F. S. (2016). Location-aware workflow scheduling in supply chains based on multi-agent systems. Paper presented at the TAAI 2015 - 2015 Conference on Technologies and Applications of Artificial Intelligence.

Hsu, P.-Y., Aurisicchio, M., \& Angeloudis, P. (2019). Risk-averse supply chain for modular construction projects. Automation in Construction, 106, 102898.

Hsu, P. Y., Angeloudis, P., \& Aurisicchio, M. (2018). Optimal logistics planning for modular construction using two-stage stochastic programming. Automation in Construction, 94, 47-61.

Hsu, P. Y., Aurisicchio, M., \& Angeloudis, P. (2017). Supply chain design for modular construction projects. Paper presented at the IGLC 2017 - Proceedings of the 25th Annual Conference of the International Group for Lean Construction.

Jaafar, K., Elbarkouky, R., \& Kennedy, J. (2021). Construction site layout optimization model considering cost and safety in a dynamic environment. Asian Journal of Civil Engineering, 22(2), 297-312.

Jaśkowski, P., Sobotka, A., \& Czarnigowska, A. (2018). Decision model for planning material supply channels in construction. Automation in Construction, 90, 235-242.

Karabayir, A. N., Botsali, A. R., Kose, Y., \& Cevikcan, E. (2020) Supplier selection in a construction company using fuzzy AHP and fuzzy TOPSIS. In: Vol. 1029. Advances in Intelligent Systems and Computing (pp. 481-487).

Kayhan, B. M., Cebi, S., \& Kahraman, C. (2019). Determining and Prioritizing Main Factors of Supplier Reliability in Construction Industry. Journal of Multiple-Valued Logic and Soft Computing, 32(1-2), 111-134.

Khan, S. A., Chaabane, A., \& Dweiri, F. T. (2018). Multi-criteria decision-making methods application in supply chain management: A systematic literature. Multicriteria methods and techniques applied to supply chain management, 1 .

Kim, S.-Y., \& Nguyen, V. T. (2020). Supply chain management in construction: critical study of barriers to implementation. International Journal of Construction Management, 1-10.

Kim, S., Chang, S., \& Castro-Lacouture, D. (2020). Dynamic Modeling for Analyzing Impacts of Skilled Labor Shortage on Construction Project Management. Journal of Management in Engineering, 36(1).

Kim, T., Kim, Y. W., \& Cho, H. (2020). Dynamic production scheduling model under due date uncertainty in precast concrete construction. Journal of Cleaner Production, 257.

Kim, Y. W., Han, S. H., Yi, J. S., \& Chang, S. W. (2016). Supply chain cost model for prefabricated building material based on time-driven activity-based costing. Canadian Journal of Civil Engineering, 43(4), 287-293. 
Komsiyah, S., Wongso, R., \& Pratiwi, S. W. (2019). Applications of the fuzzy ELECTRE method for decision support systems of cement vendor selection. Paper presented at the Procedia Computer Science.

Kristy, C. N., \& Zagloel, T. Y. (2020). An Integrated Analytical Hierarchy Process and Monte Carlo Method Approach for Supplier Selection in Construction's Supply Chain. Paper presented at the ACM International Conference Proceeding Series.

Kumar, A., \& Shoghli, O. (2018). A review of IoT applications in supply chain optimization of construction materials. Paper presented at the ISARC. Proceedings of the International Symposium on Automation and Robotics in Construction.

Le, P. L., Elmughrabi, W., Dao, T.-M., \& Chaabane, A. (2020). Present focuses and future directions of decision-making in construction supply chain management: a systematic review. International Journal of Construction Management, 20(5), 490-509.

Le, P. L., Jarroudi, I., Dao, T. M., \& Chaabane, A. (2021). Integrated construction supply chain: an optimal decision-making model with third-party logistics partnership. Construction Management and Economics, 39(2), 133-155.

Leontaris, G., Morales-Nápoles, O., Dewan, A., \& Wolfert, A. R. M. (2019). Decision support for offshore asset construction using expert judgments for supply disruptions risk. Automation in Construction, 107, 102903.

Liu, D. (2012). The decision-making model of partnership portfolio on supply chain. Paper presented at the 2012 IEEE International Conference on Mechatronics and Automation, ICMA 2012.

Liu, J., \& Lu, M. (2017). Optimization on supply-constrained module assembly process. Paper presented at the IGLC 2017 - Proceedings of the 25th Annual Conference of the International Group for Lean Construction.

Liu, J., \& Lu, M. (2018). Constraint Programming Approach to Optimizing Project Schedules under Material Logistics and Crew Availability Constraints. Journal of Construction Engineering and Management, 144(7).

Liu, Y., Dong, J., \& Shen, L. (2020). A Conceptual Development Framework for Prefabricated Construction Supply Chain Management: An Integrated Overview. Sustainability, 12(5), 1878.

Mettler, T., Eurich, M., \& Winter, R. (2014). On the use of experiments in design science research: a proposition of an evaluation framework. Communications of the Association for Information Systems, 34(1), 10.

Mirghaderi, S. D., \& Modiri, M. (2021). Application of meta-heuristic algorithm for multi-objective optimization of sustainable supply chain uncertainty. Sadhana Academy Proceedings in Engineering Sciences, 46(1).

Pan, N. H., Lee, M. L., \& Chen, S. Q. (2011). Construction material supply chain process analysis and optimization. Journal of Civil Engineering and Management, 17(3), 357370.

Said, H., \& El-Rayes, K. (2012). Optimal material logistics planning in congested construction sites. Paper presented at the Construction Research Congress 2012: Construction Challenges in a Flat World, Proceedings of the 2012 Construction Research Congress.

Said, H., \& El-Rayes, K. (2013). Automated system for multi-objective optimization of construction supply and site logistics. Paper presented at the Proceedings, Annual Conference - Canadian Society for Civil Engineering.

Saini, M., Arif, M., \& Kulonda, D. J. (2019). Challenges to transferring and sharing of tacit knowledge within a construction supply chain. Construction Innovation. 
Seuring, S., \& Gold, S. (2012). Conducting content-analysis based literature reviews in supply chain management. Supply chain management: An international journal.

Son, P. V. H., Duy, N. H. C., \& Dat, P. T. (2021). Optimization of Construction Material Cost through Logistics Planning Model of Dragonfly Algorithm - Particle Swarm Optimization. KSCE Journal of Civil Engineering.

Su, Y. (2020). Selection and Application of Building Material Suppliers Based on Intuitionistic Fuzzy Analytic Hierarchy Process (IFAHP) Model. Ieee Access, 8, 136966-136977.

Taghaddos, H., Hermann, U., AbouRizk, S., \& Mohamed, Y. (2010). Simulation-based scheduling of modular construction using Multi-Agent Resource Allocation. Paper presented at the Proceedings - 2nd International Conference on Advances in System Simulation, SIMUL 2010.

Thunberg, M. (2016). Developing a framework for supply chain planning in construction (Vol. 1782): Linköping University Electronic Press.

Tserng, H. P., Yin, S. Y. L., \& Li, S. (2006). Developing a resource supply chain planning system for construction projects. Journal of Construction Engineering and Management, 132(4), 393-407.

van der Beek, T., van Essen, J. T., Pruyn, J., Aardal, K., \& Hopman, H. (2019). Optimizing inventory strategy for modular shipbuilding.

Xanthopoulos, A., Aidonis, D., Vlachos, D., \& Iakovou, E. (2012). A planning optimisation framework for construction and demolition waste management. International Journal of Industrial and Systems Engineering, 10(3), 257-276.

Yazdi, A. J., Fini, A. A. F., \& Forsythe, P. (2020). An Integrated Product Planning and Design Platform in the Context of Housebuilding Industry. Paper presented at the Construction Research Congress 2020: Computer Applications.

Zhu, M., Dai, J., Liu, R., Xu, J., \& Alwisy, A. (2021). Two-period based carbon-economy equilibrium strategy for modular construction supply planning. Journal of Cleaner Production, 290. 